\title{
El discurso de la prudencia para una buena argumentación*
}

The Discourse

of Prudence for a Good Argument

\author{
0 discurso \\ da prudência \\ para uma boa \\ argumentação
}

Primer semestre de $2019 \cdot \mathrm{pp}$. 83-94 Segunda época

№ 49

ROTIOS 


\section{Resumen}

Este artículo propone una comprensión del discurso de la prudencia para una buena argumentación desde conceptos aristotélicos. En tal ejercicio, se persigue el desarrollo de una palabra autorregulada en relación con las intenciones con que se dicen las cosas y al momento de discutir con el otro. De esta interpretación, por último, se expone la panorámica general de la argumentación y sus planteamientos sobre los géneros del discurso retórico, la lógica, la conmoción y la ética, sus fases de producción y comprensión y, como conclusión, la incidencia de su aplicación en una población de trabajo con dificultades a nivel de convivencia y a nivel argumentativo.

Palabras clave

discurso; prudencia; palabra; argumentación

Abstract

This paper proposes an understanding of the discourse of prudence to achieve a good argument based on Aristotelian concepts. The aim of this exercise is to develop a self-regulated word with regards to the intent with which people say things and when they discuss with others. Finally, and based on this interpretation, we present an overview of argumentation and its approaches to the genres of rhetorical discourse, logic, commotion and ethics, its phases of production and understanding and, in conclusion, the incidence of applying it in a population with difficulties at the coexistence and argumentative level.

\section{Keywords}

discourse; prudence; word; argumentation

\section{Resumo}

Este artigo propõe uma compreensão do discurso da prudência para uma boa argumentação desde conceitos aristotélicos. Nesse exercício, procura-se o desenvolvimento de uma palavra auto-regulada em relação com as intenções com as que as coisas são ditas e no momento de discutir com o outro. Dessa interpretação, por últimos, expõe-se a panorâmica geral da argumentação e suas abordagens sobre os gêneros do discurso retórico, a lógica, a comoção e a ética, suas fases de produção e compreensão e, como conclusão, a incidência de sua aplicação em uma população de trabalho com dificuldades a nível de convivência e a nível argumentativo.

\section{Palavras-chave}

discurso; prudência; palavra; argumentação 


\section{Introducción}

En este artículo se propone una comprensión de la argumentación para regular la palabra a partir de conceptos de la técnica retórica de Aristóteles, en sus modalidades oral y escrita; y, en cuanto a su producción y análisis, a partir de unos principios que la subordinan desde las simetrías del decir y el hacer (de forma ética), en relación con las intenciones con que se dicen las cosas. Para ello, fue necesario hacer de la argumentación un ejercicio equilibrado a través de la prudencia, que es un modo de ser del orador y la principal característica de credibilidad de su discurso, así como una forma de transmitir sus razonamientos a quien le escucha y con la base del bien común, es decir, de lo más conveniente para todos. Con este planteamiento, se resolvieron problemas en un contexto educativo, integrado por estudiantes de validación del ciclo 5B del Colegio República de Colombia de la ciudad de Bogotá, quienes oscilaban en edades entre los 15 y 65 años. Entre estos problemas, además de la edad, se presentaban: violencia psicológica ${ }^{1}$, violencia de hecho (que se reflejaba en agresiones, disputas verbales ${ }^{2}$ y poca disposición de escucha ${ }^{3}$ ), dificultades en la producción y el entendimiento de la palabra. ${ }^{4}$ Con estos problemas, se hizo visible la siguiente pregunta de investigación: ¿Por qué es necesaria una instrucción de la prudencia en el discurso para resolver problemas discursivos de la palabra en su expresión oral y escrita? ${ }^{5}$

En tal medida, surge el objetivo general de "instruir al estudiante desde la prudencia en el discurso" para resolver los problemas de la población en ambas modalidades (oral y escrita); y de este se determinan cuatro objetivos específicos ${ }^{6}$, que se presentan en los cuatro capítulos del marco teórico y en los que se incorporan la retórica y la prudencia aristotélicas, apoyándose, a su vez, en aportes de

1 Véase la descripción de la población en Moreno (2017, p. 63).

2 Véase anexo 1 en Moreno (2017, p. 90).

Véase anexo 2 en Moreno (2017, p. 90).

Véase anexo 10 en Moreno (2017, p. 94).

Véase pregunta de investigación en Moreno (2017, p. 8).

Véanse los objetivos específicos en Moreno (2017, p. 8). algunos de sus contemporáneos sobre la argumentación. ${ }^{7}$ Lo que aquí se trabajó fue un reto investigativo, que respondió a los anteriores objetivos y que se justificó a partir de la necesidad de atender las problemáticas del curso que, siendo tan heterogéneo, tenía diferencias en las estructuras formales de su desarrollo cognitivo, lo cual mostraba el retroceso de su formación en un continuum argumentativo, junto con los tiempos estipulados para el reporte de resultados, las sesiones disponibles de intervención, las ausencias de algunos estudiantes, entre otros factores. A pesar de estas limitaciones, lo que a continuación se consignan son los alcances de la propuesta, con la que se reconocen avances y cambios en las dinámicas de trabajo del curso frente a la argumentación y a su interacción. Este artículo, a través de lo anterior, se enfoca en poner el discurso de la prudencia al alcance de posibles lectores que puedan dar continuidad a lo que aquí se expone. ${ }^{8}$

\section{El cultivo de la retórica a partir de Aristóteles}

Si bien Platón (2003), maestro de Aristóteles, concebía en la retórica "la inconsistencia de un arte que no tiene más entidad que otras habilidades que producen placer" (p. 15) ${ }^{9}$, así como también la consideraba la culpable de la condena a su maestro Sócrates, por la retórica sofística de ese entonces, será Aristóteles quien le dé una nueva concepción y principios sobre los cuales esta técnica argumentativa se desarrollaría

7 Como requisito para la realización del proyecto de investigación, también se hizo necesaria la consulta de antecedentes de investigación que, si bien no son iguales o no tienen los mismos objetivos de esta propuesta, sí fueron afines y complementarios, en la medida de que no solo sirvieron para tener un panorama más sustentable sobre la teoría de la argumentación, sino también para justificar la importancia de su instrucción en varios escenarios, como lo es el educativo que tanto concierne en este proyecto. Dado el caso que se quieran consultar, estos están disponibles en el documento original, o en la misma bibliografía que aquí se referencia al final del documento, junto con las demás referencias consultadas en la investigación (Moreno, 2017).

8 En caso de que se requiera del documento original, en el que se consigna completamente "El discurso de la prudencia", este está a disposición de su lector en el repositorio de la Universidad Libre (Moreno, 2017).

9 Fragmento tomado del diálogo El Gorgias de Platón (2003, pág. 5). Este texto también se referencia en la versión de la Retórica de Aristóteles de Alianza Editorial (2002, p. 15) 
de manera más eficiente. Para este filósofo, la Retórica ideal sería aquella de la que surgen atenienses bien pensantes, personas virtuosas que fueran capaces de instruir para bien y de forma comprometida con las necesidades de la ciudad, para conducir a las almas a "desear lo verdadero y obrar en todo conforme a ello" (Racionero, 1999, p. 26). El estagirita ${ }^{10}$ la concebiría como "la facultad de considerar lo que en cada caso puede ser más conveniente", o como también lo propone Perelman (1989), la lógica de lo preferible ${ }^{11}$. La retórica, a partir de Aristóteles, tendría mayor orden procedimental al regularla con una serie de tratados o reglas que conforman un discurso ${ }^{12}$ y en el que la palabra es asertiva, ya que trata del orador, el auditorio y lo que se dice. A pesar de sus discrepancias en cuanto a la retórica, el punto de confluencia entre Aristóteles, Platón y Sócrates, estaría en que, como contribución a la belleza y a la persuasión, el fin de las técnicas o de estos primeros tratados argumentativos ${ }^{13}$ debían comprometerse a una causa mucho mayor que la de simplemente conmover a la audiencia o al juez, si se discutía en el marco de un juicio. De esa causa surgen los tres intereses de la retórica que son: la belleza, el bien y la verdad, que no se deben desconocer de manera aislada para la argumentación, ya que cada uno cumple con una función: la verdad, para sentenciar lo más acertado; el bien, sugerido para el progreso y para el común acuerdo que beneficie a todos los participantes; y la belleza, para llamar la atención de quienes participan en las discusiones. ${ }^{14}$

10 De esta manera también era conocido Aristóteles, por el hecho de que su ciudad de origen era Estagira.

11 Extraído de El tratado de la Argumentación. Nueva retórica (1989), de Chaïm Perelman y Olbrechts Tyteca, que se cita en la versión temática de la Retórica de Aristóteles (2000).

12 Discurso, para Christian Plantin (2015), se entiende como una serie de actos planificados con el fin de obtener algo (p. 14). A partir de esta noción, se construye, de una manera más amplia, lo que aquí se entiende por discurso, pero teniendo en cuenta que, para la retórica aristotélica, este discurso retórico consiste en lo que es más conveniente para todos, que se compromete con lo verdadero, antes que a otro fin particular del orador o de quien emite y defiende el asunto tratado, bajo lo que aparentemente concibe como verdad.

13 De estos tres tratados argumentativos que se mencionan, estarían la retórica aristotélica, la dialéctica platónica y la mayéutica socrática

14 Sobre la búsqueda de la belleza, Aristóteles defendió la importancia que tenía en la educación el ritmo de la poesía para el alma humana, en una "interrelación entre lo individual y lo social" (Caponnetto, 2000).
Así, Aristóteles construye una noción en la comunicación para cada uno de estos elementos: el que habla, a quien se habla y lo que se dice ${ }^{15}$, los cuales ya se señalaban atrás. Estos también se pueden entender como el ser para el que habla, el pensar para lo que se dice y el proferir para el individuo al que se habla. Estas tres nociones del discurso se inscriben en los tres pilares que el estagirita determinó para la retórica: el ethos, el pathos y el logos. El ethos estaría representado en el ser; el pathos, en el proferir; y el logos, desde el pensar. De estos tres pilares nace la palabra y la retórica que la encierra; y, en conjunto con sus géneros y fases de producción y análisis, se conforman la prudencia y el discurso, cuyo concepto se amplió con base en la definición de Plantin (2015), teniendo en cuenta que, para el estagirita, se hablaba solo de las cosas valiosas (las del bien común, que no incluían la mentira, ni la especulación u otras que degradaran la argumentación). En otras palabras, un hombre ético y prudente no utiliza la palabra que cause perjuicio o daño al bien común.

\section{Géneros discursivos de la retórica: judicial, epidíctico y deliberativo}

La temporalidad de la retórica reside en sus tres géneros discursivos, pues cada uno atiende a un momento específico del tiempo, del cual se obtienen argumentos, evidencias, ejemplos, hipótesis y constataciones. Dependiendo del tipo de oyente y el escenario en el que se discuten temas referidos a la vida pública y a necesidades prácticas, se proponen estos géneros para desarrollar la retórica: los géneros deliberativo, judicial y epidíctico, o demostrativo. Estos tratan varios asuntos desde un momento del tiempo en específico, por lo cual funcionan para hablar de temas referidos al pasado, al presente y al futuro. En ese sentido, el género judicial trata temas referidos al pasado; el epidíctico, del presente; y el

15 Este vendría siendo el primer modelo comunicativo que propone Aristóteles en 0 ccidente. Este modelo, en la actualidad, se conoce directamente como emisor para el que habla, receptor para el que escucha 0 a quien se habla, y mensaje para lo que se dice, el cual, a su vez, es la base de la teoría del modelo lineal de la información de Shannon y Weaver (1949). 
deliberativo, del futuro, de lo que puede ocurrir u ocurrirá. Estos tres géneros se encargan de discernir, juzgar, exaltar, reprochar o aconsejar, a partir de unos fines que se inscriben en cada tipo de género (Aristóteles, 2000; Plantin, 2015; Marafioti, 2003). Estos fines son:

- Género judicial: lo justo y lo injusto.

- Género epidíctico (demostrativo): lo honroso y lo deshonroso.

- Género deliberativo: lo útil y lo perjudicial.

El judicial corresponde, en un sentido convencional, a escenarios de carácter político, en los que se da la producción de prescripciones que, traducidas en leyes, regulan las normas sociales sobre las que se tiene que regir la vida pública, apelando siempre al mejor criterio, es decir, a aquello que ya se ha discutido en el pasado y que sigue aplicando en la actualidad, desde una lógica deductiva. Sin embargo, esto no indica que lo judicial deba ejercerse únicamente en espacios jurídicos, pues también puede ser integrado dentro del habla y los espacios del común. Lo epidíctico, que ilustra una lógica inductiva, tiene que ver con los arquetipos, o los ejemplos dignos de imitar y promover en sociedad. Ya que trata de lo honroso y lo deshonroso, este se encarga de dar juicios de valor a las acciones y a quienes las ejercen en el presente, junto con sus atributos, sus virtudes y sus beneficios, así como los reproches a las malas acciones y a los malos sujetos, a las malas intenciones y a todo lo que genere perjuicio, representado, como se dijo previamente, en acciones o en individuos. De este género se distinguen dos categorías: el encomio y el vituperio.

El encomio es la alabanza; el vituperio, el reproche. Por ejemplo, si el orador quiere encomiar al educador, resaltará sus atributos primordiales, como su conocimiento, su capacidad de transmitirlo, entre otras cualidades de dicho individuo, de tal manera que se promueva su imagen y sus acciones como un modelo a seguir. Si, por el contrario, se quiere vituperar al que delinque, se apela a sus malos hábitos, a sus vicios, así como a las acciones que afectan el bien común y que, por ende, deben evitarse. Por último, está el género deliberativo, que se preocupa por aconsejar sobre lo venidero, sobre el futuro y la forma en la que el sujeto es exhortado o disuadido de realizar una acción. De la deliberación se pueden distinguir los argumentos de causa y efecto, que se construyen en la proposición de manera condicional, es decir, de la siguiente manera: "Si haces el mal, recibirás de la parte un mal peor"; "Si se es sabio, lo más probable es que se tomen las mejores decisiones". En otras palabras, cuando se habla de lo deliberativo, lo que se pretende es aconsejar a los sujetos de las posibles consecuencias de sus acciones, para bien o para mal, de tal forma que siempre se apele al mejor criterio, o a lo más conveniente ${ }^{16}$, con el fin de evitar el perjuicio. En el caso del maestro, el más prudente, este es el que delibera con más conocimiento y le muestra al otro más posibilidades para la realización de cualquier acción.

Estos géneros acercan al orador a varios escenarios, incluidos los cotidianos y sus usos; contribuyen a una aproximación al criterio de verdad, haciendo que se pueda contar con intencionalidades más claras y concretas sobre los asuntos que cada discurso pueda tratar; por ejemplo, en el caso de lo judicial, que permita manifestar la opinión soberana, prescrita dentro de la ley, para que esta sea lo más equilibrada y razonada posible; o en caso de que se hable de leyes cuya aplicación es nula o injusta en la actualidad, esta pueda ser discutida por los ciudadanos corrientes. Por esto, la retórica también aproxima al individuo corriente a su realidad política. En cuanto a los otros dos géneros, que sirven para exaltar lo bello y reprochar lo nocivo (demostrativo) y para aconsejar y ayudar a tomar mejores decisiones (deliberativo), estos contribuyen a que todos tengan unos mismos referentes comunes, que se adquieren por las vías de la argumentación, para llegar siempre a lo que ya se ha llamado antes, desde Aristóteles, el mejor criterio, o lo más conveniente.

16 Cabe resaltar que de esto deriva el interés del auditorio, si se tiene en cuenta que todo sujeto está inspirado por un interés especial (Galindo, 2016). 


\section{Ethos, pathos y logos: la palabra virtuosa, conmovedora y razonada}

Los intereses en los estudios de Aristóteles de la Retórica estuvieron ligados a la manifestación de la belleza y a la estructura de la poesía. Aunque Aristóteles reafirme la autonomía en las disciplinas de la Poética y la Retórica, también reconoce que estas dos tienen ciertos "campos en común" (Suñol, 2007), en búsqueda de lo verdadero, lo bello y lo virtuoso. Estos tres se consideran principios. Si se parte del pathos, este tiene que ver con la disposición del orador sobre la audiencia, es decir, que de la actitud de quien habla se pueda adecuar a la actitud del mismo público, de quien escucha lo que se dice, a la vez que el orador también puede influir en el comportamiento de dicho público. Estas disposiciones se generan desde las emociones que se pueden transmitir o con las que quien habla se puede dirigir a su público. En ese sentido, si se habla con disposición amorosa, la audiencia se pondrá en dicha disposición; si, por el contrario, la disposición es de odio, quien escucha adoptará esta misma disposición.

Con muchos más sentimientos, y dado que la palabra se mueve en el mundo de la emoción, la audiencia se puede disponer de varias maneras; sin embargo, dependiendo de la emoción del momento, se reconoce que esta puede afectar el juicio de quien escucha, por esa misma máxima que propone Aristóteles en el pathos, en la que define al ser como un animal político (Aristóteles, 1954, p. 15) que se rige entre la pasión y la razón. Por ello, la actitud y la disposición del momento en el que se desarrolla el discurso influyen en cómola audiencia lo recibey en la que saca conclusiones de este. De esta disposición depende el uso de la palabra, así como la puesta en escena del orador, entendida como actio, con la que se puede generar una buena disposición que permita el equilibrio entre lo pasional y lo racional.

El logos es el principio racional del discurso, que tiene que ver con la lógica argumentativa, que es con la que se construyen los argumentos. Estos, que se conforman a partir de una serie de premisas, deben tener una relación lógica entre sí, de tal manera que entre estas se llegue a unas determinadas conclusiones, productos de la relación lógica entre las dos o más premisas, o incluso entre razonamientos que forman el todo de un discurso. En otras palabras, el logos es una idea completa que se desarrolla a partir de premisas que se encadenan en razonamientos. En Aristóteles se distinguen tres tipos de razonamiento: el deductivo, el inductivo y el abductivo, los cuales, en varios o incluso en un solo discurso, se pueden presentar.

En ese orden que se exponen, la deducción se concibe como una premisa mayor que tiende a la generalidad; la inducción se refiere a la parte con la parte, que en su retórica se denomina como ejemplo o hechos factuales; y lo abductivo sería lo más cercano a la formulación de la hipótesis a partir de los hechos, es decir, que de un fenómeno perceptible se puede construir una premisa que vaya de lo particular a lo general. El mayor interés de Aristóteles siempre estuvo en la deducción, por lo cual desarrollaría un silogismo deductivo que denominó entimema. Este tipo de silogismo consiste en una generalidad expuesta en una proposición, llamada premisa mayor y con una verdad universal, que se compara con otra proposición que afirma sobre un hecho particular y que se denomina premisa menor, para que de la relación lógica entre ambos tipos de premisa se llegue a un tercer producto, que sería la conclusión. Dicho procedimiento se puede ejemplificar de la siguiente manera:

Premisa mayor: Las mujeres que tienen leche están paridas

Premisa menor: Esta mujer tiene leche (o está en periodo de lactancia)

Conclusión: Esa mujer está parida
a) Premisa mayor b) Premisa menor

\section{c) Conclusión}

A partir de este esquema, se consolida cada elemento que conforma la tesis, representada en la premisa mayor; las evidencias, que sustentan la tesis a partir de hechos factuales; el ejemplo, o lo que se entiende como razonamiento inductivo, identificable en la premisa menor; y, por último, la conclusión que surge de la relación lógica entre ambas premisas, como se muestra en el ejemplo de las mujeres. 
De las consideraciones hechas para la aplicación de esta lógica argumentativa con la población de trabajo, fue necesario aclarar las nociones entre lo general y lo particular, siendo la generalidad en las proposiciones lo que puede considerarse, en términos de deducción, una afirmación con un razonamiento de carácter universal, es decir, aplicable para cualquier realidad; mientras que lo particular sería lo inductivo, que aunque sea factual, no puede llegar a considerarse general, si carece de sistematicidad o de varios hechos factuales que la determinen como algo más que una simple inducción o una abducción (hipótesis). Esta línea de razonamiento, sobre lo general y lo particular, fue pertinente en la medida de que procura evitar la falacia, o una afirmación falsa que pretenda hacer de algo particular algo general (falacia de la generalización que, a nuestro modo de ver, es la más general de todas, ya que incluso obvia la que le sigue, que es el olvido de alternativas, y que según Weston [1994] son las dos falacias que encierran las demás falacias).

De esta forma, con base en la lógica de la argumentación, o principio de logos, se comprenden también las particularidades que surgen de una generalidad. Por ejemplo, cuando se dice lo siguiente:

Premisa mayor: Los hombres altos tienden a ser adultos.

\section{Premisa menor: Pablo es alto.}

Conclusión: Pablo es adulto.

Este ejemplo concluye con que "Pablo es adulto". Sin embargo, la particularidad estaría en el hecho de que Pablo puede ser un menor de edad alto, por lo cual, aunque generalmente se tenga como deducción que los hombres altos son adultos, lo más conveniente es considerar las implicaciones de dicha proposición, de tal forma que esta no se emita sin tener en cuenta la excepción que dicho hecho factual representa. En ese sentido, lo más adecuado sería afirmar que "la mayoría de hombres altos son adultos", mas eso no quiere decir que todos los hombres altos lo sean, así como tampoco implicaría que todos los hombres bajos de estatura sean menores de edad. En cuanto a lo inductivo, o la premisa menor que funciona como ejemplo o evidencia de la tesis, se puede contar con varias premisas que justifiquen la premisa mayor. De ese modo, se rescata la importancia de contar con diversas pruebas que justifiquen y corroboren cada afirmación, siempre y cuando exista la correlación lógica entre ambos tipos de premisas, a partir de lo cual se obviaría la falacia del olvido de alternativas y, por ende, la de generalización.

En el principio del ethos, surgen las intenciones de la palabra de parte de quien habla. Si bien en las disposiciones del pathos se mencionó aquello de conmover a quien escucha desde la sutileza de la palabra bella, para Aristóteles no es suficiente que esta cautive y persuada, pues si se retoma lo de lo más conveniente para todos, las intenciones del orador se encaminan a garantizar una causa mayor y prioritariamente social: la del bien común, que en este caso es la ética. Este bien común es aquello que conviene entre lo privado y lo público, que evita el perjuicio y apela al principio de verdad, que se representa en el logos y sobre el cual el orador se abstiene de caer en falacias, injurias, malas intenciones y disposiciones, dándole así a su discurso, junto con el carácter del orador, una reputación virtuosa, de prestigio o, desde el encomio del género epidíctico, digno de honra. De este pilar es del que más se desprende la prudencia, que es la principal cualidad del orador, ya que esta se manifiesta en un modo de ser representado en las acciones y en las palabras de quien habla, de tal forma que este adquiera la concepción del hombre maduro ${ }^{17}$, quien siempre tiene presentes el ethos, el pathos y el logos, constituyendo así una palabra razonada desde la técnica (que es la retórica); una palabra bella desde los términos más convenientes y las disposiciones de ánimo; y una palabra virtuosa, transparente y creíble para quien la escucha.

17 Aristóteles distingue tres modos de ser representados en tres edades: el viejo, el joven y el hombre maduro. La madurez de este último reside en el equilibrio de los modos de ser de las otras dos edades, siendo así un arquetipo de individuo pasional y racional, con proyección optimista del futuro y prudente, es decir, con buenas disposiciones e intenciones frente a sus actos y palabras. 
El ser prudente es un ser comprometido con la verdad, que se abstiene de defender lo indefendible, de condenar a un inocente por coacción, por injuria o por solamente delinquir. La prudencia, sin embargo, no consiste solamente en una actitud de transparencia y de imparcialidad de parte del modo de ser que define al orador, sino que también es traer a quien escucha a la verdad de quien habla; $y$, en términos de instrucción, es la voluntad con la que el orador enseña la técnica, es decir, instruye a la persona, no solo para entender su discurso, sino para brindarle el razonamiento argumentativo, que es la construcción de argumentos, regalándole así al otro la lógica y la palabra para su propio porvenir. En esos términos, el orador prudente adquiere la potestad de maestro y se rige por una voluntad pedagógica, con la cual transmite una verdad y la forma de llegar a ella, para que quien escucha, o en términos de educación, de quienes sean sus discípulos, sean ciudadanos bien pensantes, que reproduzcan con otras audiencias (que en este caso son audiencias educativas), este tipo de discurso, que es el de la prudencia.

Estos tres pilares, en suma, se ven desarrollados en unos procedimientos de producción (procedimientos encadenados que son: el inventio, el dispositio, el elocutio, la memoria y el actio) y el análisis del discurso (introducción, desarrollo y conclusión) que Aristóteles asume como técnicas. Estas son básicas en la instrucción y formación de la palabra prudente para los estudiantes.

\section{Fases de producción y análisis de la retórica}

Las fases de producción y análisis son la base para la construcción y el desarrollo de la palabra razonada (logos) y de la palabra bella (pathos). De estas se puede decir que surgen procedimientos para la elaboración del discurso argumentativo, que incluye, para el caso de lo oral, la puesta en escena pública, o la presentación de lo que se dice a quien se habla. Empezando por el inventio, este procedimiento puramente argumentativo es el que busca los argumentos y las razones que los van a sostener y que se van a usar en el discurso. Lo que para Plantin en la argumentación (2015), se entiende como un proceso lógico, en el que $X$ sustenta a $Y$. Así, $X$ (premisa[s] menor[es]) sustenta(n) a $Y$ (premisa mayor); y de esa relación lógica entre ambos tipos de proposiciones/premisas, surge un tercer producto, que aquí se puede denominar $Z$, y que sería la conclusión. También se consideran, en esta fase, los posibles contraargumentos de la tesis a defender, así como el tipo de disposición de la posible audiencia, es decir, la actitud, el tipo, la importancia que tiene el discurso para quien lo escucha.

El procedimiento del dipositio ilustra la textualidad del discurso, es decir, la organización de los razonamientos y el orden esquemático con el que se desarrollan en este. Esto se remite al exordio (Marafioti, 2003), que es el comienzo del discurso y el anuncio, cuando se menciona en qué consiste lo que se dice y el objetivo principal de este, que se reduce al captatio benevolentiae, que es la atención y el comportamiento con el que el auditorio se dispone para recibir el discurso; y el partitio, que es cuando se expone al oyente la forma en la que todo el enunciado ${ }^{18}$ se organiza y se va desarrollando a medida que se emite. El dispositio plantea un esquema general de lo que el discurso va a tratar, desde el principio, el desarrollo y su conclusión, preocupándose por la exposición de los hechos que conforman una causa, o lo que se quiere demostrar o juzgar, a partir de una estructura argumentativa.

Esta se puede identificar fácilmente por la conformación de una introducción, en la que se expone una síntesis general del asunto del discurso, la tesis a defender, los tópicos para desarrollar la argumentación y el objetivo de esta; un desarrollo, en el que se explican los términos, se desarrollan las ideas y se distribuyen los argumentos; $y$, por último, la conclusión, ${ }^{19}$ cuya función principal no se preocupa

18 El enunciado, en términos de los griegos, se entiende como todo discurso construido a partir de proposiciones, mas no de la manera en que se interpreta ahora el concepto de enunciado, que se refiere, por ejemplo, a una de sus acepciones, como a la de la oración simple.

19 La función de este procedimiento textual no se limita únicamente a contribuir a la producción del discurso, sino que a su vez permite su análisis, en la medida de que le da a su receptor, ya sea en lo escrito o en lo oral, un esquema de organización en el que puede identificar la distribución del contenido, así como la función de cada uno de los párrafos que conforman la argumentación. 
por retroalimentar lo anteriormente referenciado a lo largo del discurso, sino que su prioridad está en ser un producto de la relación lógica entre la tesis y los argumentos, de tal forma que esta tenga un carácter propositivo, que incite a la reflexión continua sobre el asunto que discute el discurso.

El elocutio, lo lingüístico, lexis y taxis, o léxico y orden, o "las palabras adecuadas, la forma de las frases, las oraciones que dan cuerpo a los argumentos previamente definidos" (Malaver, 2012, pág. 8) es el procedimiento que sigue al dispositio. En este se pone en práctica el término más conveniente para hacer bella la palabra y darle un atractivo al discurso, del cual los oyentes se sientan atraídos. De las formas de expresión que Aristóteles rescata de su poética para su retórica, la conveniente es la prosa, ${ }^{20}$ que se vale de la metáfora ${ }^{21} \mathrm{y}$ del símil para añadir fuerza al estilo de los argumentos. ${ }^{22}$ Lo importante no es solo embellecer con estilo la sentencia, o la conclusión, sino también articular cada elemento de la lógica argumentativa, es decir, cada proposición, para así construir una oración compuesta, en la que se relacionen y se redacten las oraciones correspondientes a las premisas y a la conclusión. Como contribuyente, los conectores lógicos funcionan como palabras que unen oraciones y dan un sentido conjunto. Estos conectores se emplean de varias formas: como adverbio, preposición, elementos de coordinación, yuxtaposición, etc. Sintetizando el elocutio, Aristóteles propone cinco

20 Pues se parte del habla popular, que es algo propio de la gente. Retomando algo de La poética (Aristóteles, 2011), la prosa debe parecer lo más natural posible, pues de lo contrario, si el discurso se percibe de forma artificial, a su vez el oyente infiere que quien habla finge. Por tanto, entre verso y prosa, ya que el primero es más exagerado, el segundo es más conveniente para la identificación de una expresión común y no pretendida, o sobreactuada.

21 La que aquí se trabaja es la metáfora proporcional con la que se da la relación entre dos términos, que funcionan en un mismo campo de comparación.

$22 \mathrm{Y}$ de ello derivan los argumentos por analogía, en los que las proposiciones y la conclusión se expresan de una manera más conveniente y conmovedora (véase, para una mejor comprensión del tema de la analogía, Malaver, 2014). Para el caso de las premisas menores, entendidas también como inducciones o como ejemplos, en la retórica aristotélica (2000) adquieren un carácter anecdótico, cuando una argumentación se narra o se expone en forma de cuentos, de fábulas, chistes o diversos modos de expresión que se acerquen al habla cotidiana. condiciones para garantizar el buen estilo y los fines de este procedimiento:

- Usar conectores necesarios, pero no más de la cuenta.

- Llamar a las cosas por su nombre, sin rodeos y sin exageraciones.

- Evitar la ambigüedad.

- Distinguir los géneros de los nombres: masculino, femenino y neutro.

- Usar bien el singular y el plural.

La memoria, como procedimiento, está ligada a la creencia del alma como entidad perfecta, en la cual, cuando algo queda fuertemente impregnado en ella, incluso, en términos de san Agustín, "no se diluye en la temporalidad de las vivencias del yo". En ese sentido, la memoria es una prioridad que da al orador mayor prestigio, en el sentido de que lo que sabe lo retiene en el alma sin la necesidad de depender del texto escrito, únicamente con lo que ya reside en su mente. El acto de conocer sus argumentos de memoria también añade características de elocuencia a quien habla, pues da noción de mayor claridad de ideas a quien escucha. Además, de la memoria se obtiene más coherencia y fluidez en el discurso, al independizarse del contenido escrito.

Como último procedimiento de producción para formar la palabra prudente, se encuentra el actio, que se encarga de lo prosódico, lo cual también comunica o permite, en un sentido práctico, dar imagen de confianza, de precisión y de convicción en quien habla. Se fija en mecanismos que acompañan al discurso: la voz y la expresión. La voz puede ser alta, baja o regulada y media. Las entonaciones pueden ser aguda, grave o intermedia. Estos tonos dan musicalidad al discurso y disponen a la audiencia, pues si bien el volumen es muy alto y grave, puede indicar agresividad del orador; si, por el contrario, es baja y aguda, da la noción de poca convicción en sus palabras. La expresión tiene que alejarse de la frialdad, pues de ser fría, expone lo bueno y virtuoso con matices de indiferencia, lo cual resta la importancia que el orador atribuye a su discurso. 
A manera de conclusión de este apartado, hay que mencionar que, así como la retórica cuenta con cinco procedimientos de producción, a su vez tiene una fase de análisis de la palabra prudente, que es la que permite que el discurso sea entendido por la audiencia. Se necesita de un análisis para que lo que se dice no tenga malinterpretaciones ni confusiones, pues se debe garantizar siempre el mutuo entendimiento, porque de otra forma no existiría un mensaje satisfactoriamente transmitido. Toda fase, así como todo análisis, debe tener clara una estructura. En la de la retórica, esta estructura consta de una introducción, un desarrollo y una conclusión. Aunque este orden en el dispositio se ve en gran parte, es importante que el análisis tenga en cuenta el cuerpo del discurso, es decir, con qué inicia, qué argumentos se han usado, qué título (si tiene) se usa y cómo se relaciona con lo que se dice. Desde la lógica se analizan los argumentos, que deben ser razonados y de los cuales hay que percatarse de que han sido constituidos como tal. En caso contrario, el análisis ayuda a entrever si lo que se dice es razonado, posible o simplemente es una falacia, de acuerdo con la misma lógica de los tres tipos de razonamientos que aporta Aristóteles y que se señalaron atrás.

\section{Metodología de investigación}

Este trabajo de investigación tiene un enfoque mixto, ya que emplea herramientas y ejercicios ${ }^{23} \mathrm{de}$ medición cuantitativa, así como otros ejercicios e instrumentos de recolección de datos de corte cualitativo. La instrucción de los contenidos de la retórica se llevó a cabo por medio de lecturas colectivas con la teoría correspondiente, en la que también estuvieron presentes las menciones sobre el concepto aristotélico de la prudencia. Para la identificación de avances y mejoras en la población de trabajo en la argumentación, la técnica fue evaluada por medio

23 Véase Moreno (2017, pp. 83-89; 90-112), las estadísticas y los anexos. En estos últimos se incluyen los talleres de aplicación de esta investigación, junto con los instrumentos de medición y recolección de información para el diagnóstico inicial, así como los instrumentos de evaluación sobre la efectividad y viabilidad de la propuesta. de pruebas objetivas (Cerda, 2002), con las que, valiéndose de los datos estadísticos, se llegaron a conclusiones frente a la aprehensión y retención de información de los estudiantes en cuanto a la técnica argumentativa. Del otro lado, la incorporación de la prudencia fue registrada por medio de los diarios de campo, en los que se incluyen los acontecimientos durante las intervenciones, así como los cambios actitudinales de la población.

En esa medida, se optó por utilizar el método hipotético-deductivo, el cual tiene como "objeto de estudio al hombre, su conducta y sus relaciones" (Delgado y Gutiérrez, 1994). A partir de ese principio, se observó, se diagnosticó, se evaluó, se hizo una propuesta y se validó frente a la población en cuestión. Todo esto siempre tuvo en cuenta comportamientos y relaciones existentes entre estudiantes, presentados antes y durante las intervenciones, con el fin de dar solución al problema encontrado. De ahí surge la hipótesis de investigación, que sostiene que el discurso de la prudencia permite resolver los problemas de producción y análisis de la palabra, al igual que sus usos en las relaciones interpersonales de la población de trabajo. ${ }^{24}$

Para garantizar la validez de la hipótesis frente a las intervenciones, se procedió a partir de los siguientes criterios: la precisión de las explicaciones $y$ las predicciones, procurando tener una rigurosa medición de los datos observados, registrados en los diarios de campo, junto con los datos obtenidos con instrumentos cuantitativos; la convergencia de pruebas variadas e independientes, como soporte para la triangulación entre los objetivos de investigación, los constructos teóricos aquí referenciados, las aplicaciones durante la investigación y el análisis de resultados; y con el apoyo mutuo de la teoría, que en este caso es la de Aristóteles. ${ }^{25}$ De tal hipótesis surgieron seis categorías de análisis, que se representaron en las cinco fases de producción y análisis

24 Véase descripción del problema en Moreno (2017, p. 5).

25 Estos tres criterios se mencionan en el mismo documento que se cita y en el mismo párrafo en el que se incluyen, variando el último criterio de José Cegarra (2012), que habla del apoyo mutuo entre teorías, en: Los métodos de investigación. 
de la retórica, junto con el principio de prudencia en el discurso, el cual estuvo presente en todas las intervenciones. ${ }^{26}$

\section{Resultados}

De esta investigación, se obtuvieron dos resultados finales: primero, se reconocieron avances en cuanto a la producción y análisis de la palabra por parte de los estudiantes, teniendo en cuenta que de la palabra prudente trabajada hubo pequeños grados de aprehensión de las técnicas de cada procedimiento, al igual que algunas consideraciones sobre las funciones de los géneros discursivos. Los logros más evidenciables, referentes a la técnica, tienen que ver con el inventio, sobre la lógica argumentativa y principio de logos, puesto que de este procedimiento se reconocieron las nociones de la tesis, los hechos factuales que la corroboran y la conclusión, como producto de la relación lógica entre proposiciones; no obstante, aunque en lo práctico se distinga una considerable aprehensión de dicho procedimiento, queda por trabajar la terminología sobre la lógica, pues hubo ausencias de retención de esta por parte de varios estudiantes. Del actio, hubo notoria mejora en cuanto a la dicción y pronunciación de los estudiantes, en razón de las lecturas colectivas de cada aplicación, así como una mejor confianza en la oralidad al momento de hablar en público.

El dispositio y el elocutio presentaron mayor dificultad de aprehensión, a comparación de los otros dos procedimientos ya mencionadas, pues de esta primera el cuerpo textual requiere de mayor trabajo en cuanto a la introducción y conclusión del discurso; mientras que del elocutio, se sugiere mayor formación de los estudiantes en relaciones semánticas, así como lo referente al uso de metáforas, de tal forma que se superen las dificultades de estos en el desarrollo de un continuum analógico. Adicionalmente, el punto de mayor distinción de este procedimiento fue el de la unión de las proposiciones con los conectores lógicos. De los géneros discursivos, el judicial fue el de menor comprensión,

26 Véase Moreno (2017, pp. 66-78; 95-11), talleres de aplicaciones y análisis de resultados. mientras que los deliberativo y epidíctico fueron más fáciles de aprender y aplicar en sus escritos.

El segundo resultado es el referente a la prudencia, que es el más evidenciable en la formación de los estudiantes, y sobre el cual se identificaron los logros más representativos de esta investigación, pues su incidencia se muestra en los siguientes aspectos: cambio de disposición frente a los contenidos y con el docente, lo cual indica, a su vez, una mejor escucha a quien les habla; trato interpersonal, al observar la disminución de hostilidad entre ellos; reconocimiento de sus debilidades en su proceso de formación, como puede señalarse a partir de varias de sus reflexiones sobre las cuales identifican qué tan eficiente ha sido su formación en conocimientos y habilidades, que forman parte de las consideraciones sobre hablar o abstenerse de ello; y en la transmisión de sus ideas con base en la lógica argumentativa y en unas nociones más claras sobre lo general y lo particular.

\section{Conclusiones}

La investigación, a pesar de que dio resultados parciales, puesto que la técnica no alcanzó a ser aprehendida en su totalidad, implementó la palabra prudente, que se hizo propia y fue incorporada en la interacción entre la misma población (estudiante/ estudiante(s), y estudiante(s)/profesor(es)), así como la disposición, la moderación y las reflexiones sobre aquello que los estudiantes saben y aquello que no. Se sugiere esta propuesta para futuras investigaciones, que le den continuidad a los logros aquí alcanzados y con condiciones más ideales en cuanto al tiempo disponible, la presencia de todos los estudiantes en todas las sesiones, las garantías de no deserción, entre otros factores que fueron influyentes en los resultados finales de esta investigación. Queda, por último, con lo que aporta esta investigación, la sugerencia de formar a más estudiantes en la técnica con el fin de mejorar el desarrollo de razonamientos deductivo, inductivo y abductivo, que redundarían en la interacción, frente a los problemas de violencia de hecho y simbólica que presenta la población del colegio.

La retórica, para finalizar, cuenta con varias líneas de razonamiento que se mencionan en el 
principio de logos, y que aquí no se incluyen en razón de las acotaciones académicas requeridas para la presentación final de este trabajo. No obstante, estas pueden presentarse como posibles vías de desarrollo, dada la posibilidad de dar continuidad a la propuesta con mayor énfasis en la lógica argumentativa.

De todas formas, el marco teórico original, con mayor extensión y planteamientos sobre esta técnica argumentativa, está a disposición de quien se interese por retomar lo aquí expuesto con mayor amplitud. La prudencia aristotélica también puede ser considerada como posible vía de desarrollo en otras investigaciones basadas en la ética en la comunicación, así como procesos argumentativos en otras técnicas, como podrían ser los casos de una prudencia en la dialéctica, una prudencia en la mayéutica, o una prudencia en la pragmadialéctica, entre otras modalidades y técnicas que requieran de una palabra en función de lo prioritariamente social.

A quien se interese por el tipo discurso aquí planteado, ha de entender que este se dispone para estudiantes y docentes, por lo cual es necesaria su apropiación y puesta en práctica para quien se instruye e instruye a los demás en este modo de ser manifestado en la palabra y las intenciones con que se dicen las cosas. En últimas, se requiere de la concordancia entre el ser, el pensar y el proferir de parte de quien pretenda usarlo, para no alterar los fines prudentes de esta propuesta. Queda, como conclusión final, el término ideal que se propone para la formación de estudiantes y docentes, la voluntad pedagógica con la que se dicen las cosas, las intenciones con las que se configura la perspectiva del otro, la posibilidad de hacer de debates, conversaciones y demás escenarios en los que se comprometa la palabra algo dialógico, que permita mejorar las relaciones entre individuos y nos acerque a ese criterio de verdad, belleza y bien común. Así que, tal y como concluye la retórica y en palabras similares a las del estagirita: "Hasta aquí se ha hablado, juzguen ustedes".

\section{Referencias}

Aristóteles (1954). La política. Barcelona: Editorial Iberia. Aristóteles (2000). Retórica. Madrid: Alianza.

Aristóteles (2011). La poética. Madrid: Gredos.

Caponnetto, A. (2000). Retórica, Historia y Poesía en el pensamiento de Aristóteles. Buenos Aires: Gladius.

Cerda, H. (2002). La evaluación como experiencia total. Bogotá: Cooperativa Editorial Magisterio.

Cegarra, J. (2012). Los métodos de investigación. Colección monografías. Madrid: Ediciones Díaz de Santos.

Delgado, J.M. y Gutiérrez, J. (1994). Métodos y técnicas cualitativas de investigación en ciencias sociales. Revista Andaluza de Relaciones Laborales, 3, 163-168

Galindo, J. (2016). El arte de la oratoria. Bogotá D.C.: Departamento de Publicaciones Universidad Libre.

Malaver, R. (2012). Argumentación para la educación. Bogotá: Universidad Distrital Francisco José de Caldas.

Malaver, R. (2014). El poder de la analogía. Artículo presentado en el año 2014 como uno de los exámenes de candidatura exigidos por el Doctorado en Educación. Sin publicar. Convenio Interinstitucional Universidad Pedagógica Nacional, Universidad Distrital Francisco José de Caldas y Universidad del Valle. Bogotá.

Marafioti, R. (2003). Los patrones de la argumentación. Buenos Aires: Biblios.

Moreno, J. (2017). El discurso de la prudencia para una buena argumentación. Sin publicar. Bogotá.

Perelman, C. y Tyteca, L.O. (1989). Tratado de la argumentación. Nueva retórica. Madrid: Gredos.

Platón (2003). Diálogos. Volumen ll: Gorgias. Madrid: Editorial Gredos

Plantin, C. (2015). La argumentación. Barcelona: Planeta.

Racionero, Q. (1999). Retórica de Aristóteles. Madrid: Editorial Gredos S.A.

Shannon, C.E. y Weaver, W. (1949). La teoría matemática de la comunicación. Chicago: Prensa de la Universidad de Illinois.

Suñol, G. C. (2007). La Retórica y la Poética de Aristóteles: sus puntos de confluencia. La Plata: Departamento de Filosofía Universidad Nacional de La Plata.

Weston, A. (1994). Las claves de la argumentación. Barcelona: Ariel S.A. 